\title{
THE ROLE OF CHLORPROMAZINE IN THE MANAGEMENT OF PSYCHIATRIC PATIENTS
}

\author{
By G. F. Vaughan, M.B., M.R.C.P., D.P.M. \\ Chief Assistant, Guy's Hospital, London; Consultant Psychiatrist, Wood Vale Reception Centre
}

Chlorpromazine is one of the best known of the many new drugs which have been introduced into medicine and psychiatry under the title of ' tranquillizers.'

It is probably not a curative drug. In schizophrenia, for example, its benefits are largely symptomatic. However, this failure to provide a cure in no way detracts from its value as a special 'sedative' and ' resocializing' agent.

It is used extensively for its action in controlling psychomotor and psychotic over-activity, which it does without causing excessive somnolence 'or confusion. In fact, psychomotor over-activity appears to be the group of symptoms most influenced, rather than any particular nosological category.

The main indications for its use are in toxic confusional states, acute and chronic psychoses, mania, senile and pre-senile dementia and certain childhood disorders. It is of less value in psychoneurotic or depressive conditions, and as sideeffects are common, and may be serious, it is doubtful if it is suitable for patients outside hospital, except under careful supervision.

\section{Pharmacological Properties}

The chemical and pharmacological properties of chlorpromazine have been described in detail by Courvoisier (1953) and Dundee (1954).

Chlorpromazine is a derivative of phenothiazine and is closely related chemically to phenergan and lysivane. It has anti-adrenaline, anti-acetylcholine and anti-histamine activity, as well as a strong local anaesthetic action, and it potentiates barbiturates and other anaesthetics and sedatives.

Absorption is rapid from the intestine. The action is maximal at one hour, with appreciable effects at six hours and some activity at 24 hours. Since only 7 per cent. of the dose administered is excreted in the urine in three days, most of the drug is presumably metabolized in the body, though the route is unknown.

There is evidence that chlorpromazine, like reserpine, acts on the mesencephalic and diencephalic parts of the brain, especially the hypothalamus and the mesendiencephalic alerting system of Moruzzi and Magoun (1949) and Jasper (1949). The mesendiencephalic alerting system influences general cerebral function and behaviour; it acts as a vast relay and distribution centre on the afferent side-stimulation produces wakefulness and alertness, while depression induces sleep. Stimulation of part of this system produces Parkinsonism, as has been shown by Ward, McCulloch and Magoun (1948). In small doses chlorpromazine sedates this alerting system, but in larger doses it stimulates it, and in large doses it may also produce a Parkinsonian state. Through the hypothalamus chlorpromazine influences endo-? crine function and may cause lactation and menstrual disturbances. Also through its effect on these areas it causes a fall in blood pressure and an increase in the heart rate.

The importance of these areas in the control or production of disturbances of behaviour and emotion, and also in the regulation of the level of awareness and consciousness, has been stressed in recent years (Ingram, 1952; Pond, 1954). And it would seem that drugs which particularly influence these parts of the brain may be expected to affect disturbed behaviour profoundly.

From the chemical point of view it has been suggested that chlorpromazine may act through its effect on serotonin or 5-hydroxy-tryptamine, though its exact action is not yet clear (Gyermek, 1955). This neurohumoral agent is present in plain muscle and brain tissues and it has been suggested that excess may result in abnormal mental states (Wooley and Shaw, 1954).

Under the influence of chlorpromazine patients may appear dreamy, calm, listless, indifferent and apathetic, but the overall effect is unlike that produced by the barbiturates, which render the patient drowsy. Contact can be made with patients, though they may seem indifferent to the environment and show lessened anxiety. 


\section{LLOYD-LUKE}

\section{Books that enshrine profound thought}

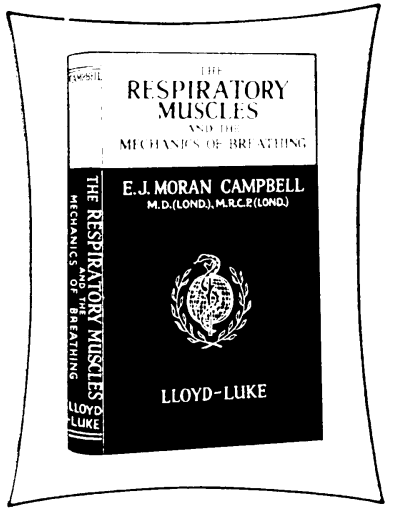

THE RESPIRATORY MUSCLES

E. J. Moran Campbell $x v i+132$ PP. 32 illus.

Ready shortly

\section{Lloyd-Luke}

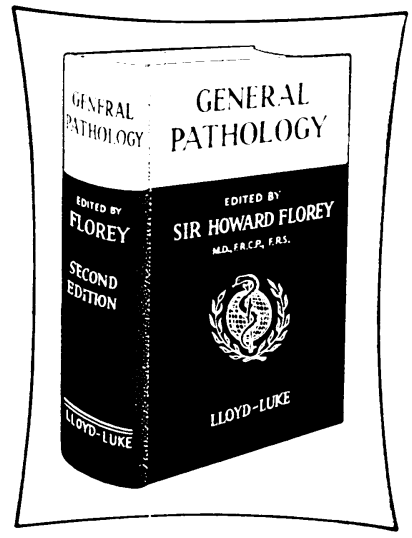

GENERAL PATHOLOGY (2nd edit.)

SIR HOWARD FLOREY $x v i+932$ pp. 410 illus. 3 colour plates

Ready shortly

845.

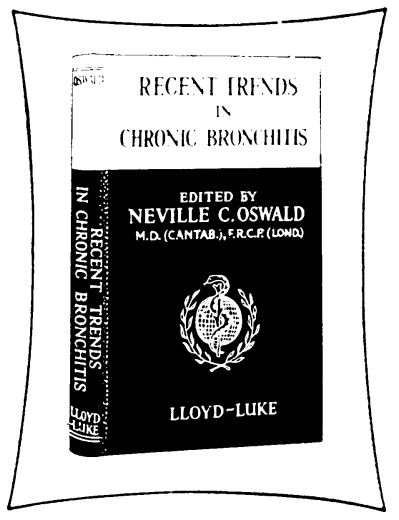

RECENT TRENDS IN CHRONIC BRONCHITIS NEVILLE C. OsWALD viii +200 pp. 76 illus. 2 colour plates About 30s.

\section{Dosage}

Individual responses are extremely variable and the dose must be determined for each patient. Dosage up to $2,000 \mathrm{mg}$. a day can be tolerated by adults, though at these levels Parkinsonian symptoms may develop. It is usual to begin with $75 \mathrm{mg}$. or $100 \mathrm{mg}$. daily by mouth, gradually increasing the dose as necessary. There is probably no advantage in exceeding $600 \mathrm{mg}$. or $800 \mathrm{mg}$. daily.

For rapid action the intramuscular or intravenous routes should be used. The 2.5 per cent. solution should be diluted about io times with saline before being injected intravenously. Deep intramuscular injection is well tolerated, though it may occasionally cause pain at the site of the injection. The elixir of chlorpromazine $(+\mathrm{ml}$. contains $25 \mathrm{mg}$.) is rapidly absorbed and in some instances is more effective than tablets.

Chlorpromazine can be combined with other physical treatments, such as insulin coma and E.C.T. For prolonged sleep chlorpromazine may be combined with barbiturates, such as amytal and phenobarbitone, and anti-histamines, such as phenergan, and in physically fit adults may be continued up to a month without difficulty.

\section{Side-effects}

These are frequent and for this reason it is doubtful if it is suitable for patients outside hospital, except under careful supervision. Dizziness, palpitations, shivering, lethargy and colicky abdominal pains are all common, but usually pass off after a few days' treatment. Skin rashes are more serious, but jaundice and agranulocytosis are the complications most to be feared. Large doses may produce a Parkinsonian syndrome, and the drug is also mildly epileptogenic. As a rule complications are not serious and disappear when the dose is reduced or administration discontinued. Surprisingly, they do not usually recur when the drug is restarted.

Jaundice may be due to intra-hepatic obstruction and any interference with biliary drainage may predispose to this complication. Chlorpromazine should therefore probably not be given where there is a history of liver disease.

When lethargy and weakness are a problem chlorpromazine may be reduced or combined with either d-amphetamine or phenidyl-acetate (Ritalin).

It must also be remembered that this and similar drugs potentiate the effect of barbiturates and alcohol and should not be given when unknown quantities of these have been taken. A contact dermatitis or a photosensitization reaction may be a troublesome complication where staff repeatedly handle chlorpromazine (Lewty, I955). 
This is much more likely to occur if the dispensed material is in solution. Where it is being used extensively precautionary measures should be adopted similar to those used for the control of sensitivity reactions in staff handling antibiotics.

\section{Psychoses}

Chlorpromazine reduces psychotic tension, restlessness and over-activity and calms the aggressive behaviour associated with acute and chronic psychotic disorders (Vaughan, Leiberman and Cook, 1955). Communication is improved and social rehabilitation follows, so that, in addition to an immediate and largely sedative response, psychotic patients may show a slow process of reintegration and improved social functioning which extends over many weeks before the maximum effect is seen. For this reason the drug should be continued for at least four to six weeks before deciding that it is not having the desired effect on the patient.

Patients who are a continual source of disturbance may become quiet, co-operative, occupied and able to leave hospital for short periods of leave. Their relatives find new interest in their welfare, and this is a further indirect help in their social recovery. With the most disturbing elements of a community treated in this way a ward atmosphere may improve and other patients also become settled, socially improved and more responsive in the quieter environment.

The indications for prescribing chlorpromazine in psychiatry are generally similar to those for reserpine. Chlorpromazine is usually more effective more quickly and is less unpleasant for the patient. Reserpine acts more slowly over a longer period and, while the number of unpleasant sideeffects is much greater than for chlorpromazine, there are none of the serious complications of chlorpromazine, such as jaundice and agranulocytosis. Rinaldi, Rudy and Himwich (1956) have studied the comparative action of reserpine, chlorpromazine and frenquel on chronic schizophrenia and claim that they are effective in that order. Reserpine and chlorpromazine are much more active than frenquel, with reserpine more effective for the catatonic and chlorpromazine more effective for the paranoid groups.

\section{Toxic Confusional States}

In toxic confusional states, alcoholic delirium and other conditions in which a rapid effect is required, repeated intramuscular doses of 75 to roo mg., combined with general measures for restoring fluid and vitamin levels, are usually adequate.

\section{Senile and Pre-senile Dementia}

Chlorpromazine may reduce over-activity and confusion in these conditions, and is particularly useful when combined with other sedatives at night. In rare instances it may increase confusion. Patients may respond satisfactorily to quite small doses, such as 50 or $100 \mathrm{mg}$. daily or even less.

\section{Mania}

About 50 per cent. of cases of mania will respond rapidly and in combination with E.C.T. the majority can be controlled.

\section{Depression}

Reactive depression is generally unresponsive to chlorpromazine and endogenous depression responds better to E.C.T. Where there is marked agitation, however, chlorpromazine may assist, but E.C.T. remains the treatment of choice.

\section{Psychoneuroses}

Here opinions differ widely and some authorities consider chlorpromazine useful for controlling anxiety. However, it does not appear to be a substitute for other methods of treatment. Obsessionai states and hysterical states, for example, are helpe $\overline{\mathbb{Q}}$ little, if at all, and such patients are often alarme by the subjective sensations produced by the drug.

\section{Children's Disorders}

One hesitates to recommend a drug for children which may have serious complications, but it may be of value for some severely over-active and aggressive children and certain brain-damaged children characterized by over-activity and insomnia. Dosage is from to to $200 \mathrm{mg}$. daily, according to the age of the child.

\section{BIBLIOGRAPHY}

COURVOISIER, S., FOURNEL, J., DUCROT, R., KOLSKY, M., and KOETSCHET, P. (1955), Arch. int. Pharmacodyn., 92, 305.

DUNDEE, J. W. (1954), Brit. F. Anaesth., 26, 357.

GYERMEK, L. (r955), Lancet, ii, 724.

INGRAM, W. R. (1952), Electroenceph. clin. Neurophysiol., 4, 397 . JASPER, H. H. (I949), Ibid., x, 405 .

LEWTY, H. (1955), Pharm. F., 175, 463.

MORUZZI, G., and MAGOUN, H. W. (1949), Electroenceph. clin. Neurophysiol., I, 455.

POND, D. A. (1954), Proc. roy. Soc. Med., 47, 775.

RINALDI, F., RUDY, L. A., and HIMWICH, H. E. (1956), Amer. F. Psychiat., I12, 678

VAUGHAN, G. F., LEIBERMAN, D. M., and COOK, L. C. N (1955), Lancet, $i$, 1083 .

WOOLEY, D. W., and SHAW, E. (1954), Proc. nat. Acad. Sci. (Wash.), 40, 228. 